\title{
Seroprevalencia de Anticuerpos contra Brucella canisen Perros del Distrito de Pucusana, Lima, Perú
}

\author{
Seroprevalence of Antibodies against Brucella canis in Dogs of THE \\ Pucusana District, Lima, Peru
}

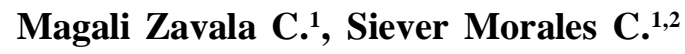

\section{Resumen}

El presente estudio tuvo como objetivo determinar la seroprevalencia de anticuerpos contra Brucella canis en perros del distrito de Pucusana, Lima, Perú. Se colectaron 202 muestras de sangre de perros mayores a 6 meses de edad de diversos grupos raciales, sexo e historial reproductivo. El análisis de los sueros se realizó mediante la técnica de inmunodifusión en gel de agar (IDGA). El 21.3 $\pm 2.9 \%$ (43/202) de los perros resultó seropositivo a anticuerpos contra $B$. canis. Se evaluaron las variables sexo, raza, ocurrencia de abortos y presencia en las calles, encontrándose asociación significativa entre la seropositividad a $B$. canis y el sexo $(\mathrm{p}<0.05)$.

Palabras clave: brucelosis canina, Brucella canis, seroprevalencia

\section{Abstract}

This study aimed to determine the seroprevalence of antibodies against Brucella canis in dogs of the district of Pucusana, Lima, Peru. Blood samples from 202 dogs older than 6 months of age were collected, regardless of breed, sex or reproductive history. The sera was analysed by the technique of agar gel immunodiffusion (AGID). The results showed $21.3 \pm 2.9 \%(43 / 202)$ of dogs seropositive for antibodies against $B$. canis. The variables sex, breed, occurrence of abortion and street presence were evaluated resulting significant association between seropositivity to $B$. canis and $\operatorname{sex}(\mathrm{p}<0.05)$.

Key words: canine brucellosis, Brucella canis, seroprevalence

\footnotetext{
${ }^{1}$ Laboratorio de Microbiología y Parasitología Veterinaria, Facultad de Medicina Veterinaria, Universidad Nacional Mayor de San Marcos Lima, Perú

${ }^{2}$ E-mail: sieverm@hotmail.com
} 


\section{INTRODUCCIÓN}

La brucelosis canina es una enfermedad ampliamente distribuida a nivel mundial (Carmichael, 1990; Berthelot y Garin, 1993; Carmichael y Shin, 1996; Wanke, 2004). La infección de Brucella canis ocurre a través de la mucosa oronasal, vaginal y conjuntival. La transmisión sexual durante el apareamiento es la más frecuente. La contaminación no sexual ocurre en casos de aborto por contacto con las secreciones, o por ingestión de fetos, placenta y descargas vaginales de perras infectadas (Johnson y Walker, 1992), donde pueden encontrarse en concentraciones superiores a $10^{10}$ bacterias $/ \mathrm{ml}$ (Carmichael y Shin, 1996). Asimismo, perros de ambos sexos eliminan la bacteria por la orina y en el caso de machos, además, por el semen (Carmichael y Joubert, 1988).

En general, los signos de la brucelosis no son muy evidentes (Carmichel, 1976; Carmichael y Joubert, 1988). La pirexia no es común, y a veces se presenta pérdida de la condición corporal y del pelaje así como ocasional intolerancia al ejercicio; sin embargo, los signos clínicos varían según el órgano afectado (Shin y Carmichael, 1999; Borie et al., 2002; Wanke, 2004), habiendo principalmente abortos tardíos en hembras, epididimitis y prostatitis en machos, e infertilidad, linfadenitis y discoespondilitis en ambos sexos (Carmichael y Greene, 1993). El aborto se presenta entre la séptima a novena semana (rango de 45-59 días de gestación) en el 75\% de los casos (Carmichael y Shin, 1996; Borie et al., 2002). En los casos de gestación a término, algunos nacen muertos y los que sobreviven se encuentran débiles y pueden morir en 1 a 3 días (Johnson y Walker, 1992; Agudelo et al., 2014).

El diagnóstico de la brucelosis canina es a través del aislamiento bacteriológico. Sin embargo, esto no siempre es posible, por lo que existen técnicas serológicas, como la prueba de inmunodifusión en gel de agar (IDGA), que utiliza antígenos de la pared celular, mostrando bandas de precipitación específicos contra B. canis (Briceño et al., 2004).

En el Perú se tienen antecedentes de estudios de prevalencia de brucelosis canina. Así, Reyes (1977) encontró 28\% (54/196) de muestras positivas a la prueba de aglutinación en tubo 2-mercaptoetanol en el área de Lima Metropolitana. En otro estudio, en perros residentes en los distritos de Bellavista y Callao (Lima), se reportó el 15.7\% (71/456) de canes positivos a la prueba de IDGA (Ramírez et al., 2006). El presente estudio tuvo como objetivo determinar la prevalencia de anticuerpos contra brucelosis canina en el distrito de Pucusana, Lima, Perú.

\section{Materiales y Métodos}

\section{Lugar de Estudio y Animales}

El presente estudio se llevó a cabo en el distrito de Pucusana, al sur de la ciudad de Lima, el cual tiene una superficie aproximada de $46 \mathrm{~km}^{2}$ y una población estimada de 10633 habitantes (INEI, 2007). El criterio de selección del área se basó en las características epidemiológicas tomando los índices de NBI (necesidades básicas insatisfechas) del año 2005 , que presentó un promedio de $47 \%$, el cual expresa la carencia de condiciones básicas de higiene y una gran cantidad de caninos que deambulan en contacto con personas, así como con posibilidades de acceso al lugar (INEI, 2007).

Se trabajó con canes machos y hembras de diversas razas y cruces. Los animales fueron seleccionados según los siguientes criterios de inclusión: mayores de 6 meses de edad con sospecha de deambulación (hábitos peri-domiciliarios) y que los dueños dieran el consentimiento para realizar el estudio. Se aplicó un cuestionario, donde se registraron datos como identificación del animal, raza, sexo, edad, facilidad de paseos en exteriores, enfermedades previas e historial reproductivo (apareamientos, preñez y problemas reproductivos, incluyendo abortos). 
Cuadro 1. Asociación de las variables raza, edad, historia reproductiva (abortos) y sexo con la positividad a la prueba de Inmunodifusión en Gel de Agar (IDGA), mediante la prueba de Chi Cuadrado $(\mathrm{p}<0.05)$

\begin{tabular}{llccc}
\hline Variables & & Positivo & Negativo & P \\
\hline Raza & Cruzado & 32 & 102 & \\
& Perro Peruano sin & 2 & 20 & 0.276 \\
& Pelo & 9 & 37 & \\
& Otras razas & 9 & 58 & \\
Edad & 0.5 a 1 & 16 & 72 & 0.992 \\
(en años) & $>1$ a 5 & 19 & 29 & \\
& $>5$ & 8 & 46 & \\
Ocurrencia de & No & 16 & 5 & 0.245 \\
aborto & Sí & 5 & 1 & \\
& Se desconoce & 1 & 104 & 0.047 \\
Sexo & Macho & 21 & 55 & \\
& Hembra & 22 & & \\
\hline
\end{tabular}

${ }^{1}$ Incluye a hembras en edad reproductiva $(n=74)$

\section{Muestreo}

El muestreo se realizó entre julio a setiembre de 2009 en tres campañas de salud que se llevaron a cabo en la Plaza de Armas, así como a través de visitas a domicilio en los diversos sectores del distrito. El tamaño mínimo de muestra (n=202) fue obtenido aplicando el método de cálculo del tamaño de la muestra para estimar una proporción, tomándose como referencia una prevalencia de $15.6 \%$, según trabajos previos (Ramírez et $a l ., 2006)$ y un nivel de confianza del $95 \%$.

Se recolectaron muestras de sangre por punción de la vena cefálica o de la safena. Los tubos de sangre se colocaron en una gradilla a la espera de la retracción del coágulo y se llevaron con gel refrigerante al laboratorio de microbiología de la Facultad de Medicina Veterinaria de la Universidad Nacional Mayor de San Marcos en Lima. El suero se obtuvo mediante centrifugación, se transfi- rió a viales de $2 \mathrm{ml}$ y se almacenó en congelación.

\section{Análisis de Laboratorio}

Se utilizó la prueba de Inmunodifusión en Gel de Agar (IDGA), que consiste en una reacción de precipitación en fase líquida entre el antígeno y el anticuerpo, formando bandas visibles de precipitación (Tizard, 1998). Esta técnica tiene la ventaja de emplear un antígeno de brucelas rugosas que contiene un lipopolisacárido específico (como B. canis o $B$. ovis) y que no presenta reacciones cruzadas con otras especies de brucela en su forma lisa (Véliz et al., 1974). La IDGA es una prueba cualitativa, por lo que se consideran positivos los sueros que reaccionan con el antígeno formando la banda de precipitación dentro de 24 a 48 horas, y negativos los sueros que no forman bandas de precipitación (Hollett, 2006). 


\section{Resultados}

El estudio se hizo con 202 perros, encontrando una prevalencia de $21.3 \pm 2.9 \%$ (43/202) de presencia de anticuerpos contra brucelosis canina. La asociación estadística entre la variable diagnóstico a través de la prueba de IDGA y variables como raza, sexo, edad e historial de aborto indicó únicamente asociación significativa con el sexo $(p<0.05$; Cuadro 1).

La frecuencia de perros machos y hembras positivos a anticuerpos contra brucelosis canina fue de $16.8 \pm 3.3 \%$ (21/125) y $28.6 \pm$ $5.1 \%$ (22/77), respectivamente. Asimismo, los perros peruanos sin pelo presentaron una positividad de $9.1 \pm 6.1 \%$ (2/22), en tanto que para los perros mestizos fue de $23.9 \pm 3.7 \%$ $(32 / 134)$ y para otras razas fue de $19.5 \pm 5.8 \%$ $(9 / 46)$.

\section{Discusión}

No se dispone en el país de información de brucelosis canina en perros con hábitos peri-domiciliarios que habitan en zonas carentes de condiciones básicas de higiene, como ocurre en el distrito de Pucusana, donde existe un alto índice de necesidades básicas insatisfechas - NBI (INEI, 2007). Asimismo, es importante considerar que América Central y del Sur son consideradas áreas de presentación de brucelosis canina (Castro et al., 2005; Hollett, 2006).

El $21.3 \pm 2.9 \%$ de perros con presencia de anticuerpos contra brucelosis canina es superior al $15.6 \%$ reportado por Ramírez et al. (2006) en los distritos de Bellavista y Callao, utilizando la misma técnica de laboratorio. Se observó diferencia significativa entre sexos (machos: 16.8\%; hembras: $28.67 \%$; $\mathrm{p}<0.05$ ); no obstante, la literatura científica indica que no existe predisposición por sexo para infectarse con B. canis (Carmichel, 1976; Carmichael y Joubert, 1988; Carmichael y Shin, 1996; Hollett, 2006). Es posible que la mayor cantidad de perros machos (125) en relación a hembras (77) en el presente estudio pudiera haber afectado el resultado.

En relación a las razas, el Perro Peruano sin Pelo era la raza más popular en el distrito, en tanto que la población de perros cruzados fue mayoritaria; sin embargo, no se encontraron diferencias por efecto del grupo racial a la infección por B. canis (Cuadro 1), tal y como se reporta en otros estudios (Carmichael y Shin, 1996; Boeri et al., 2008). Por otro lado, tampoco se encontraron diferencias significativas entre perros con y sin historial de abortos, así como entre perros con hábitos domiciliarios (salida controlada a la calle) y con hábitos peri-domiciliarios (actividades fuera del domicilio sin control). En este último caso, en un estudio similar en Buenos Aires, Argentina, donde además se incluyeron perros vagabundos, tampoco se encontraron diferencias significativas entre grupos (Boeri et al., 2008). Es posible que el mínimo contacto con el exterior represente una exposición a posibles contagios a través de la orina y secreciones vaginales de canes infectados.

El diagnóstico de la infección por $B$. canis es fundamental para que el control y prevención (Castro et al., 2005). Las técnicas de laboratorio, incluida la IDGA, facilitan el diagnóstico y los médicos veterinarios deberían favorecer su empleo, especialmente considerando el carácter zoonótico de esta enfermedad (Hollett, 2006).

\section{Conclusión}

Se determinó una prevalencia de $21.3 \pm$ 2.9\% (43/202) de anticuerpos contra Brucella canis en el distrito de Pucusana, Lima. 


\section{Literatura Citada}

1. Agudelo P, Molina V, Arias V, Madrigal E. 2014. Estudio serológico de brucelosis canina en dos albergues del Municipio de Envigado, Colombia (2011). Rev Fac Med Vet Zoot 61: 134-141. doi: 10.15446/rfmvZ.v61n2.44676

2. Berthelot X, Garin-Bastuji B. 1993. Brucelloses canines. Point Vet 25(152): 33-37.

3. Boeri E, Escobar GI, Ayala SM, SosaEstani S, Lucero NE. 2008. Brucelosis canina en perros de la ciudad de Buenos Aires. Medicina (B. Aires) 68: 291-297.

4. Borie C, Cepeda R, Villaroel M, De los Reyes M. 2002. Descripción de características reproductivas en tres perros seropositivos a Brucella canis. Arch Med Vet 34: 111-116. doi: 10.4067/S0301732X2002000100012

5. Briceño H, Páramo RM, Flores $R$, Súarez F. 2004. Problemas reproductivos en perros machos infectados con Brucella canis. Vet Méx 35: 121-128.

6. Carmichael LE, Joubert JC. 1988. Transmission of Brucella canis by contact exposure. Cornell Vet 78: 63-73.

7. Carmichael LE, Shin SJ. 1996. Canine brucellosis: a diagnostician's dilemma. Semin Vet Med Surg (Small Animal) 11: 161-165.

8. Carmichael LE. 1976. Canine brucellosis: An annotated review with selected cautionary comments. Theriogenology 6: 105-116. doi: 10.1016/0093691X(76)90007-8

9. Carmichael LE. 1990. Brucella canis. En: Nielsen KH, Duncan JR (eds). Animal brucellosis. Florida, USA: CRC Press Boca Raton. p 336-350.

10. Carmichael LE, Greene CE. 1993. Brucelosis canina. En: Enfermedades infecciosas de los perros y los gatos. México DF: Interamericana McGrawHill. p 604-616.

11. Castro H, González S, Prat M. 2005. Brucelosis: una revisión práctica. Acta Bioquím Clín Latinoam 39: 203-216.

12. Hollett RB. 2006. Canine brucellosis: outbreaks and compliance. Theriogenology 66: 575-587. doi: 10.1016/ j.theriogenology.2006.04.011

13. Johnson C, Walker R. 1992. Clinical signs and diagnosis of Brucella canis infection. Comp Cont Educ Pract Vet 14: 763-772.

14. Ramírez H, Calle S, Echevarría L, Morales S. 2006. Prevalencia de brucelosis canina en dos distritos de la Provincia Constitucional del Callao. Rev Inv Vet Perú 17: 39-43. doi: 10.15381/ rivep.v17i1.1456

15. Reyes F. 1977. Diagnóstico serológico de brucelosis canina causada por Brucella canis en Lima Metropolitana. Tesis Bachillerato. Lima: Univ Nacional Mayor de San Marcos. 26 p.

16. Shin S, Carlmichael LE. 1999. Canine brucelosis caused by Brucella canis. In: Carmichael LE (ed). Recent advances in canine infectious diseases. Ithaca, NY: International Veterinary Information Service. [Internet]. Available in: www.ivis.org/advances/Infect_Dis_ Carmichael/shin/chapter_frm.asp?LA=1

17. Tizard I. 1998. Inmunología veterinaria. $5^{\text {a }}$ ed. México: Ed Interamericana McGraw Hill. 558 p.

18. Véliz N, Rosadio R, Barreto D, Castagnino D. 1974. Difusión en agar gel. Prueba de campo para el diagnóstico de la epididimitis a Brucella ovis. Rev Inv Pec IVITA-UNMSM 3(1): 23-28.

19. Wanke M. 2004. Canine brucellosis. Anim Reprod Sci 82-83: 195-207. 